\title{
COOPERATIVAS: UMA POSSÍVEL TRANSFORMAÇÃO IDENTITÁRIA PARA OS TRABALHADORES DO SETOR INFORMAL?
}

\author{
Christiane Girard Ferreira Nunes
}

Resumo: Buscamos, neste artigo, refletir sobre o impacto identitário e as dinâmicas que dele resultam a partir de diferentes formas de inserção no mundo do trabalho, mais especificamente, a partir da socialização dos trabalhadores do setor informal e das cooperativas. Consideramos, portanto, estes três elementos, que ressaltamos: os trabalhadores do informal que recebem entre um e três salários mínimos; os trabalhadores das cooperativas cuja remuneração se situa em torno do mesmo patamar; algumas noções para refletir sobre a identidade no trabalho e, por fim, os vínculos entre esses três elementos a fim de perceber as mudanças que se produzem numa parte importante do mundo que vive do trabalho.

Palavras chaves: cooperativa, setor informal, trabalhador, identidade, laços sociais.

\section{Introdução}

Este artigo se apóia em três pesquisas que realizamos nos últimos dois anos. Duas de âmbito regional, junto com outro pesquisador, o doutor Mário Theodoro, do IPEA, e a terceira na esfera nacional e internacional.

Das pesquisas regionais, uma se intitula Mercado informal, desafios e perspectivas no $D F$, e teve por objetivo focalizar três atividades tidas como informais e que respondem pela absorção de uma

Christiane Girard Ferreira Nunes é doutora, professora do Departamento de Sociologia da UnB. Agradecimentos a Tânia Cruz e a Isabel Pojo do Rego pela colaboração.

Liandra Ribeiro, Helena A. Borges Correa, Gabriel Moura Peter colaboraram como estagiários de pesquisa. 
parcela significativa da força de trabalho. Trata-se do comércio de rua, do trabalho doméstico e, finalmente, do trabalho autônomo de reparação e/ou reforma na construção civil. Em conjunto, essas atividades compreendem um contingente significativo da força de trabalho no DF, correspondendo a $15 \%$ da PEA ocupada. Entrevistamos mil pessoas e consideramos as várias regiões representadas no Distrito Federal. Essa pesquisa foi encomendada pela Secretaria do Trabalho do Governo do DF.

A segunda pesquisa regional apresenta o perfil socioeconômico da população do Varjão, área de invasão no tecido urbano de Brasília. Nesses perfis estão elencadas as principais informações que delinearam o perfil da área propriamente dita, no que diz respeito ao grau de escolaridade, faixa etária, ao aspecto migratório e, ainda, à questão de gênero na condição de chefe de família e suas implicações. Foi associada à situação do mercado de trabalho em suas especificidades. Por fim, fizemos algumas considerações de cunho mais substantivo sobre as possibilidades de ações, tendo em vista informações tais como possibilidades de integração comunitária. A pesquisa faz parte do Projeto "Habitar" (Banco Mundial).

A terceira pesquisa refere-se à Economia solidária, análises $e$ perspectivas, coordenada pela UNITRABALHO. O objeto da pesquisa é constituído pelo conjunto das organizações coletivas de trabalhadores, cujas características permitem identificá-las como agentes propulsores de um novo solidarismo econômico popular no Brasil. A pesquisa focaliza, empiricamente, as iniciativas de caráter econômico e solidário que desenvolvem atividades produtivas e se organizam sob a forma de associações, cooperativas, grupos informais, oficinas e microempresas. No primeiro ano, foi feita uma sondagem preliminar que visava estabelecer um perfil geral do EES e, no segundo ano, análises de caráter mais substantivos.

Sobre a problemática da identidade que iremos abordar, gostaria de ressaltar que além de pesquisar sobre o tema desde minha tese de doutorado, sou membro do grupo de Sociologia Clínica.

Portanto, nosso objetivo, neste trabalho, é refletir sobre o impacto identitário e as dinâmicas que dele resultam a partir de diferentes formas de inserção no mundo do trabalho, mais especificamente, a partir da socialização dos trabalhadores do setor informal e das cooperativas. 
Consideramos, pois, estes três elementos, que ressaltamos: os trabalhadores do informal que recebem entre um a três salários mínimos; os trabalhadores das cooperativas cuja remuneração se situa em torno do mesmo patamar; algumas noções para refletir sobre a identidade no trabalho e, por fim, os vínculos entre esses três elementos a fim de perceber as mudanças que se produzem numa parte importante do mundo que vive do trabalho.

\section{A fragilidade do informal}

Quando sublinhamos, neste ensaio, que nos referimos a uma significativa parcela do mundo do trabalho é, em parte, porque $58 \%$ da população encontra-se no informal. Aqueles que ganham entre um a três salários mínimos no Brasil (setores formal e informal) representam em torno de $66 \%$ da população (DIEESE, 2202). Mesmo que não possamos citar os números exatos sobre aqueles que ganham entre um e três salários mínimos, no setor informal, porque seria necessário considerar as diferentes regiões, sabemos que o setor informal concentra no seu interior a grande maioria da população que trabalha nos pequenos comércios e nos empregos com baixa formação profissional.

Em primeiro lugar, é importante deixar claro que o que chamamos de informal é, ao mesmo tempo, extremamente amplo e impreciso, pois, existem inúmeras definições. Este aspecto já foi considerado pela maioria dos pesquisadores que estudam o tema, por isso, não o abordaremos novamente neste artigo (ver Noronha 2001; Nunes e Theodoro, 2001; Lautier, 1991-1999).

Nesse sentido, fazendo uma rápida referência a Lautier (1991), consideramos como inserção no setor informal, quando estamos diante de um pequeno montante de capital, uma baixa formação formal no nível da educação e, mais comumente, de uma inserção parcial na esfera jurídico-legal, lembrando que estamos nos referindo àqueles que se enquadram no patamar de remuneração acima citado. Não ignoramos que essas remunerações, no informal, podem ser até bem maiores, tanto numa condição semilegal, quanto numa condição ilícita.

Está claro, também, que aquilo que chamamos de informal adquire contornos particulares segundo a história dos mercados nacionais de 
trabalho, e segundo a época histórica considerada. A fragilidade da inserção de certas categorias de trabalhadores nos países ditos centrais, como a dos trabalhadores que realizam trabalho precário ou parcial, pode relembrar algumas dinâmicas das formas de vulnerabilização ou de exclusão no Brasil, sem contudo, na nossa opinião, ser possível compará-las facilmente, pois, referem-se, em grande parte, à história dos mercados de trabalho e de assalariamento de cada país, bem como às características das crises em cada país e de seus impactos.

Castel (1995), no seu famoso e já clássico livro, utiliza a expressão "entrar no sistema de assalariamento" como um processo que permitiu revolucionar os vínculos sociais do Capital e do Trabalho. A generalização do assalariamento permitiu, diz ele, que a remuneração em troca de uma tarefa não seja somente: garantir precariamente a sobrevivência, mas o direito a níveis mais amplos de consumo de massa, a certos tipos de lazer de massa e, sobretudo, à proteção social. O preço pago por esses benefícios de integração, através de uma situação de subordinação, foi uma reconstrução da socialização operária e uma nova identidade operária.

Se a palavra e o ato do trabalho, reúnem, ao mesmo tempo, alienação e humanização (labor e work), o taylorismo e o fordismo acentuavam de forma particular essa divisão. Aceitar essa fragmentação, a inserção através da subordinação, significava renunciar a pensar e contentar-se em executar. $\mathrm{O}$ que não significa, como mostram certos autores, que as ações dos operários no trabalho não se resumem somente a atos mecânicos, mesmo que os pesquisadores, bem intencionados, só os imaginem realizando tarefas embrutecedoras.

No entanto, foi preciso quase um século nos países ditos centrais para que se realizasse a socialização operária, ou seja, fazer de um homem no trabalho, um trabalhador. De certa maneira, isso significa dizer que foi preciso "positivar" o trabalho e o trabalhador. Se no século XIX se falava em "classes trabalhadoras e perigosas", um século depois, falase no pilar que representa para a sociedade "o trabalhador"e as virtudes ligadas a essa condição.

A transformação do homem, disperso geograficamente, ou seja, um nômade, segundo Castel e também Polanyi (2000), em um homem 
forçado a se fixar com os seus semelhantes, permite, a partir dessa mudança, que ele encontre compensações através do reconhecimento e da valorização neste novo status. Além disso, ela exige também a construção de uma nova imagem, a que encontramos na figura do operário moderno, corajoso e bom pai de família, ou na cultura operária através da cultura sindicalista que incentiva tipos de lazer saudáveis, e assim os diferencia dos burgueses parasitas. A partir daí, uma infinidade de traços característicos participam da construção de uma identidade operária.

Hoggardt (1970) também já mostrava que uma homogeneização de posições, todos na mesma situação com salários quase iguais, permitiu não somente verem-se na mesma posição que seu vizinho, tendo por exemplo o mesmo nível de consumo, mas sobretudo, se identificar e se diferenciar, ao mesmo tempo, de outros grupos sociais com remunerações mais altas. Culturalmente, "Eles" e "Nós" assim se constituem. É possível estar numa situação de pobreza, economicamente relativa, e estar realmente integrado na sua comunidade quando participamos da constituição de um "Nós". Este "Nós" se constituiu a partir da generalização do assalariamento.

No Brasil, é comum dizer que o assalariamento só existe parcialmente. As taxas de assalariamento, para dar somente um exemplo, são de $95 \%$ na França e de $45 \%$ no Brasil. Além do mais, uma boa parte daqueles que participam do setor informal (considerando o grupo com as características socioeconômicas que definimos) estiveram sempre aí incluídos. Sabemos que este crescimento regular no Brasil é devido, em grande parte, às atuais transformações do mundo do trabalho: terceirização, aumento do desemprego, diminuição do emprego na indústria. No entanto, uma boa parte desses $58 \%$ sempre estiveram no informal e nele receberam uma socialização particular.

A partir da pesquisa Atividades informais no $D F$ e, refletindo sobre a situação das três categorias socioprofissionais no Distrito Federal: comércio de rua, construção civil e empregos domésticos, juntas representando $15 \%$ do informal na região, percebemos que mais de $80 \%$ sempre tiveram empregos precários com uma grande rotatividade intraemprego, e que essa situação impera há dez anos, se considerarmos nossas pesquisas anteriores, tanto do ponto de vista do salário como das condições de trabalho. 
Tabela 1 - Percentis para o número de empregos dos últimos 3 anos

\begin{tabular}{cl}
\hline Percentis & Empregos \\
\hline 5 & 1 emprego \\
10 & 1 emprego \\
25 & 1 emprego \\
50 & 2 empregos \\
75 & 3 empregos \\
90 & 4 empregos \\
95 & 4 empregos \\
\hline
\end{tabular}

Fonte: IFPD - Instituto Fecomércio de Pesquisa e Desenvolvimento

A participação dos e das trabalhadoras nas suas comunidades é tão reduzida que $18 \%$ das mulheres são, de fato e juridicamente, chefes de família, existindo ainda uma porcentagem muito mais alta se considerarmos que elas também chefiam no aspecto financeiro, na medida em que seus maridos são os mais atingidos pelo desemprego. Observamos um crescimento da precarização, uma homogeneização dessa situação e uma fragilidade identitária, o que pode nos levar a pensar, mais à frente, na idéia de uma identidade coletiva "negativa".

Por que falar de fragilidade identitária ou até mesmo de identidade negativa? Retomaremos esta discussão mais adiante, mas devemos, desde já, considerar os elementos que conformam a identidade. A idade, o sexo e a região de origem, por exemplo, são elementos centrais. Traços comuns se distinguem: são migrantes cuja idade e cor são elementos importantes de pertencimento a grupos com mesmo grau de vulnerabilidade social.

Tabela 2 - Cor

\begin{tabular}{lcc}
\hline & Quantidade & \% \\
\hline Branca & 105 & 31.91 \\
Preta & 80 & 24.32 \\
Parda & 144 & 43.77 \\
\hline Total & 329 & 100.0 \\
\hline
\end{tabular}

Fonte: IFPD - Instituto Fecomércio de Pesquisa e Desenvolvimento 
Tabela 3 - Unidade da Federação de Nascimento

\begin{tabular}{lcc}
\hline Estado onde nasceu & Quantidade & \% \\
\hline Rondônia & 2 & 0.61 \\
Amazonas & 1 & 0.30 \\
Pará & 2 & 0.61 \\
Tocantins & 1 & 0.30 \\
Maranhão & 30 & 9.12 \\
Piauí & 48 & 14.59 \\
Ceará & 30 & 9.12 \\
Rio Grande do Norte & 10 & 3.04 \\
Paraíba & 24 & 7.29 \\
Pernambuco & 14 & 4.26 \\
Alagoas & 1 & 0.30 \\
Bahia & 58 & 17.63 \\
Minas Gerais & 35 & 10.64 \\
Espírito Santo & 1 & 0.30 \\
Rio de Janeiro & 1 & 0.30 \\
Paraná & 2 & 0.61 \\
Mato Grosso & 1 & 0.30 \\
Goiás & 46 & 13.98 \\
Distrito Federal & 22 & 6.69 \\
\hline Total & $\mathbf{3 2 9}$ & $\mathbf{1 0 0 . 0 0}$ \\
\hline
\end{tabular}

Fonte:IFPD - Instituto Fecomércio de Pesquisa e Desenvolvimento

Por outro lado, a identidade negativa (percepção de si) atua no sentido de que sua condição identitária os freia na ação social. Uma identidade que constrói um ator insignificante, pelo menos quando consideramos o sujeito a partir de sua inserção no campo do trabalho.

Temos o hábito de ressaltar que as instituições internacionais enxergaram o setor informal de maneira diferente nos últimos anos. De setor problema ele passou a ser um setor solução. Ele teria a capacidade de absorver o desemprego. No entanto, o que percebemos nas nossas pesquisas é bem o contrário: uma maior vulnerabilidade e a idéia de que é "pelo menos um trabalho", lançada pela OIT, não resolve os problemas de integração social ligados ao trabalho.

O setor informal poder ser o lugar por excelência de "viração", de criatividade. Ele pode ser visto como um lugar detentor de poucos 
meios, pouco capital, mas ao mesmo tempo, um lugar onde seus participantes engenhosamente sobrevivem. Além disso, "se virar", gerir seu capital, ser o máximo possível autônomo, corresponde exatamente a valores atuais, mesmo que não sejam tão convincentes depois que vários estudos mostraram a nossa incapacidade de improvisar como dono de restaurante, quando fomos bancário, por exemplo, considerando, neste caso, grupos bem mais favorecidos e com maior capital (financeiro, social e cultural). Neste caso podemos nos tornar proprietário de um restaurante, mas nos faltará vários conhecimentos necessários à profissão, resultando daí inúmeras falências. Nesse sentido, é simples imaginar a situação daqueles que detêm, ainda, um menor capital.

Mesmo que seja possível difundir a imagem de flexibilidade do mercado de trabalho ou de suas reconfigurações, fica claro que quando consideramos, no setor informal, aqueles que ganham entre um e quatro salários mínimos, a situação é bem outra.

Em primeiro lugar, o setor está estruturado e funciona dentro e a partir do setor formal (Theodoro e Nunes, 2000) e, nesse sentido, a desestruturação de um leva à desestruturação do outro. Para esclarecer este aspecto, citamos o nosso estudo anterior que mostra que o acesso à formação profissional dos desempregados faz deles concorrentes aos que já estão estabelecidos e desestruturam o mercado, na medida em que eles aceitam remunerações mais baixas por não possuírem experiência. Estamos mais inclinados a pensar que uma crise no setor formal corresponderia a uma crise no informal.

Nesse sentido, gostaríamos de lembrar que partimos da idéia de sistema de empregos, uma reflexão teórica particularmente desenvolvida por Freyssinet e Theodoro (2001). Esta concepção explica que as mais diversas unidades produtivas, nos mais diferentes ramos, estabelecem assim, em conjunto, uma teia de ligações de maior ou menor intensidade, de caráter associativo ou concorrencial, direto ou indireto cujo funcionamento é em parte determinado pelo quadro jurídicoinstitucional, assim como por um conjunto amplo de códigos e regras de conduta, formal ou informalmente, estabelecidas.

O sistema de emprego, dessa maneira, vai se moldando e se reproduzindo através do tempo. Mas, como afirma Freyssinet, não se trata de uma "reprodução harmoniosa". De fato, a existência e 
conformação do sistema de emprego se dá mediante um processo permanente de surgimento e de desaparecimento de unidades (grandes e pequenas), de atividades e mesmo de ramos inteiros. São atividades que se renovam e se remodelam, outras que desaparecem, outras tantas ainda que surgem e se consolidam rapidamente, a configurar um processo de "destruição, criação e recriação" da atividade econômica em seus diferentes setores e ramificações. E é nesse contexto que se explicita o fenômeno da existência das atividades ditas informais. Em uma palavra, esse tipo de atividade é resultante, basicamente, da confluência de três fatores:

- a existência de uma extrema desigualdade social, expressa não apenas em termos das disparidades de renda e de padrões educacionais, mas também na seletividade e nos reduzidos níveis de oportunidade de emprego formal vis-à-vis as dimensões da força de trabalho;

- a ausência de um marco regulatório global e institucional, que cerceie e sancione práticas abusivas e que estabeleça alguns limites e parâmetros para o funcionamento desse mercado de trabalho; e,

- a capacidade de essas atividades se articularem e se ajustarem ao sistema de emprego, estabelecendo um conjunto de estratégias de alianças e de organização que lhes possibilite a consecução ou preservação de um espaço de existência. Em síntese, o sistema de emprego compreende unidades de produção e também redes de interdependência entre essas unidades: as alianças e a concorrência. Aquilo que, de uma perspectiva mais geral, é percebido como um processo de adaptação e de readaptação do sistema, do ponto de vista da unidade, trata-se de uma luta contínua pela preservação de espaços vitais.

A análise da situação dos trabalhadores no setor informal do DF mostrou que houve um agravamento em termo de vulnerabilização para os três setores de formas diferentes. E é a partir da compreensão da idéia de sistema de empregos que refletiremos a respeito do agravamento da situação daqueles que ganham entre um e três salários mínimos, no setor informal. Para as domésticas, um empobrecimento em termos da situação familiar e social; para os ambulantes, o recrudescimento do 
controle policial; e para os autônomos da construção, uma concorrência maior e mais desemprego (Nunes e Theodoro, 2000).

\section{Os laços sociais nas cooperativas}

Como já falamos anteriormente, assistimos hoje tanto a uma reconfiguração das formas de trabalho como das formas de gestão da força de trabalho. Uma dessas reconfigurações é o ressurgimento da forma cooperativa, no contexto do setor informal que acabamos de descrever. Diante disso, como pensar as cooperativas hoje? Sem dúvida, a partir de sua heterogeneidade.

Não retomaremos a história das cooperativas neste texto, pois já foi objeto de uma de nossas pesquisas, ainda em curso, há mais de dois anos (UNITRABALHO 2000-20001). Existe uma grande variedade de cooperativas descritas pela maioria dos pesquisadores. Sua existência é um dos exemplos que mostra a transformação no mundo do trabalho, apesar de existirem há mais de um século. A história das cooperativas do Distrito Federal é bastante parecida com a que existe nacionalmente.

Tabela 4 - Por que optou por trabalhar por conta própria?

\begin{tabular}{lcc}
\hline & Quantidade & \% \\
\hline Porque o rendimento é melhor & 6 & 15.0 \\
Porque tem mais liberdade de horário & 12 & 30.0 \\
Para complementar o salário que recebe pelo & & \\
$\quad$ desempenho & 3 & 7.5 \\
Porque não conseguiu um emprego & 15 & 37.5 \\
Porque não tem patrão & 2 & 5.0 \\
Não tem estudo para trabalhar fixo & 1 & 2.5 \\
Não tem marido & 1 & 2.5 \\
\hline Total & $\mathbf{4 0}$ & $\mathbf{1 0 0 . 0}$ \\
\hline
\end{tabular}

Fonte: IFPD - Instituto Fecomércio de Pesquisa e Desenvolvimento

Está claro que o ressurgimento das cooperativas deve ser atribuído à atual crise do mercado de emprego no Brasil, assim como em várias outras regiões. Crise que se manifesta, através de uma reestruturação/ desestruturação, uma qualificação e simultaneamente uma 
desqualificação, uma nova segmentação do trabalho e um aumento do desemprego, inclusive os de longa duração. Na maioria das cidades brasileiras fala-se em $20 \%$ de taxa de desemprego e num prazo de 40 a 52 semanas para encontrar um novo trabalho. Nesse sentido, as razões que explicam o fato de pertencer ao informal ou às cooperativas (aquelas nas quais se remunera entre um a três salários mínimos) são as mesmas: falta de empregos no setor formal.

Há aproximadamente dez anos, diversas formas de cooperativas surgem por estímulo, às vezes do Estado (governo Cristóvam Buarque), dos partidos, dos sindicatos, dos movimentos populares e das associações. A situação das cooperativas, no que tange à viabilidade econômica, depende, evidentemente, de diferentes tipos de capitais: econômicos, sociais, culturais e políticos, que elas possuam.

No entanto, observamos que existe uma viabilidade social que, transpondo as fragilidades econômicas, permite que elas sejam contornadas, em razão da qualidade do vínculo social construído a partir do trabalho e através da constituição identitária que este possibilita.

Para a reflexão que nos interessa, concentramo-nos nas cooperativas cujas remunerações dos membros se situam em torno de um a quatro salários mínimos, a fim de que uma comparação entre a população do setor informal não cooperativo e do cooperativo possa ser feita, considerando diferentes formas de trabalho. Escolhemos, para refletir sobre a questão que nos colocamos (É possível uma transformação identitária quando passamos do informal não cooperativo à forma cooperativa?), reter algumas características sociais e econômicas de diferentes categorias profissionais, quais sejam: mesmo nível de formação educacional, local de residência, idade, isto é, as mesmas que as observadas no setor informal não cooperativo.

O que podemos observar nas cooperativas em termo de dinâmicas? Em relação àquelas que sobrevivem e se enquadram nas condições acima definidas (entre um, três ou quatro salários mínimos, trajeto educacional primário, etc.), elas nasceram de iniciativas populares, mais comumente por iniciativa de um ou dois membros das associações de bairro. Nos vínculos internos estabelecidos, observamos que as decisões são tomadas em conjunto, que uma remuneração mínima deve ser garantida a todos, 
e ainda, pode existir uma remuneração em função de uma produção diferenciada. O número de horas trabalhadas e os encargos assumidos são divididos pelo conjunto do grupo.

Constatamos também, a partir dessas experiências, que os projetos são pensados em comum. Os cooperados valorizam enormemente o fato de poderem dividir suas experiências particulares, as mais diferentes possíveis e vivenciadas em diferentes lugares, o que não os impede de produzir. A idéia de um "nós" se constitui e a sua ação se faz presente na comunidade de referência do grupo. Por exemplo, numa cooperativa de cabeleireiros, observada numa cidade satélite de Brasília, verificamos que ao perceber certas oportunidades políticas, seus membros fundam uma associação para conseguir terrenos da municipalidade. Não para a cooperativa, mas para ter acesso a uma habitação decente para a população dos arredores e mobilizar os habitantes para que construam eles mesmos suas casas. Da mesma maneira, fundaram uma associação de defesa contra a violência e a insegurança do seu bairro.

Notamos vários exemplos dessas dinâmicas coroadas com maior ou menor sucesso, dependendo mais comumente da origem da cooperativa e de seus interlocutores. O que observamos é que as cooperativas são sensíveis a outras necessidades que não diretamente as suas. Por isso, devemos nos questionar sobre as suas necessidades, num sentido mais amplo, e refletir sobre como responder a elas. Existe, nas relações com a comunidade, ao mesmo tempo a idéia de dar, retribuir e contribuir, ou seja, de certa forma um tipo de engajamento diferente, que não se restringe ao paradigma do mercado. Por exemplo, os membros decidem cortar o cabelo dos velhos dos hospícios ou das crianças das escolas públicas do bairro. Através das cooperativas, os membros têm normalmente a oportunidade de completar uma formação profissional mesmo que de maneira precária. Assim, a vitalidade do tecido social que antes dependia, em larga medida, dos mais diversos grupos religiosos ou do incentivo do Estado, conhece agora novos atores. Ainda que várias cooperativas sejam fundadas a partir de um pertencimento a um grupo religioso (protestantes, evangélicos) e nestes casos a socialização que permite sentimentos de pertencimentos é muito favorável ao desenvolvimento das cooperativas. 
Diversas iniciativas provenientes dos sindicatos (CUT), de empresas (terceirização, deslocamentos) ${ }^{1}$ e das igrejas, orientam seus trabalhadores na formação de cooperativas. Nesse sentido, suas configurações levantam inúmeras questões. Quais são seus valores fundamentais, sua organização, seus objetivos e sua capacidade de sobrevida econômica e social? Diferentes interlocutores exercem a função do "outro" na construção identitária dos cooperados. Assim, existem aqueles que ajudam, orientam, fazendo o jogo de intermediários com os serviços públicos. Mais elas são ajudadas, segundo seu nível de endividamento, não somente econômico mas simbólico também, mais o discurso do "outro" e suas expectativas devem ser consideradas.

Este mecanismo deverá ser analisado se desejamos refletir sobre o conceito de autonomia, fundamental na esfera do trabalho, por ser o conceito que permite compreender a pulsão de criatividade e que fornece conteúdos importantes para a construção da identidade social. Autonomia é um conceito que permite pensar ao mesmo tempo a humanização no ato do trabalho e a integração, não somente a inserção. Como nos lembra Dejours (1999), podemos fazer produzir muito sob o efeito do medo, ou da coerção, por exemplo, e por isso, produzir mais não significa um resultado que permite mensurar a criatividade. Ora, mais autonomia é o que está em jogo nas formas de trabalho das cooperativas mas, uma autonomia que deve ser pensada a partir da idéia de integração social. Porém, não estamos falando de uma individualização, conforme o pensamento durkheiminiano, mas uma conciliação desse aspecto onde acrescentamos a possibilidade de humanização do trabalho segundo a visão marxista.

No campo das cooperativas, podemos situar seus interlocutores e medir o poder de seus aliados e de seus concorrentes. Isso é importante para pensar a forma de integração na comunidade e seus limites. Como conciliar ou organizar as relações com o mercado, o Estado, a comunidade e as redes? A quem devemos dar, de quem devemos receber e a quem devemos retribuir? Nessas redes de cooperativas, por exemplo, qual é a natureza da troca? Seria uma ajuda a ser recompensada, pois cada um sabe que irá precisar do outro? Ou, seria uma troca mais livre?

No entanto, não podemos nos esquecer que do ponto de vista do mercado econômico, os concorrentes são aqueles que oferecem os 
mesmos serviços a preços inferiores e, neste caso, são normalmente as cooperativas que concorrem entre si. Este aspecto foi ressaltado nas entrevistas e é de fundamental importância. A partir dessas contradições, dos aportes, dos benefícios e das tensões na forma "cooperativa", fica impossível refletir sobre novas formas de trabalho para as categorias mais vulneráveis e o seu impacto na sociedade. Não só sobre as categorias atingidas, mas sobre a compreensão das transformações que elas promovem na sociedade. Quem são os novos atores ou interlocutores? Quais são as novas alianças ou como re-atualizar as antigas?

Mesmo que os ganhos pareçam embrionários, eles são fundamentais tanto para os sujeitos envolvidos em diversas ações e no exercício de sua capacidade em buscar soluções, como também para a multiplicação de possibilidades em assumir papéis na comunidade e, portanto, contribuir socialmente para reforçar a coesão do grupo, evitando com isso cisões. Podemos quase dizer que os benefícios "secundários", fundamentais, graças a uma pulsão, a criatividade, conservam a sua boa saúde.

A autonomia é uma das condições para a criatividade mas devemos investigar esse conceito que não deve ser separado da responsabilidade, e com isso, a partir das situações sociais é possível se reconfigurar as identidades dos trabalhadores.

Por outro lado, assistimos, no setor informal, a uma maior vulnerabilidade da situação de seus membros. As cidades periféricas, as mesmas das cooperativas que observamos, são aquelas onde a ruptura social é mais evidente, normalmente cidades-dormitório, onde o principal comércio é o ilícito. Nesse caso a participação na comunidade é ainda mais reduzida.

Tabela 5 - Você participa de alguma outra atividade civil?

\begin{tabular}{lcc}
\hline & Quantidade & \% \\
\hline Sim & 63 & 17,4 \\
Não & 300 & 82,6 \\
\hline Total & $\mathbf{3 6 3}$ & $\mathbf{1 0 0 , 0}$ \\
\hline
\end{tabular}

Fonte: IFPD - Instituto Fecomércio de Pesquisa e Desenvolvimento 


\section{O impacto identitário nas dinâmicas do trabalho}

As perguntas que levantamos referem-se à formação identitária e ao seu impacto no campo social. Quais benefícios podem ser obtidos ou quais obstáculos podem ser sofridos tanto para o sujeito quanto para a sociedade no momento em que passamos de uma situação de heteronomia no trabalho para uma situação de luta por mais autonomia?

Christophe Dejours, no seu texto A banalização da injustiça social (1996), lembra que o pensamento corrente que considerava o "fator humano", analisando as motivações e os comportamentos no trabalho, privilegiava um olhar onde o homem era visto como um sujeito que cometia falhas quase impossíveis de serem resolvidas pela gestão do trabalho. Essas falhas que mostram incompetência, distração, falta de assiduidade podem ser também uma última expressão de liberdade do trabalhador, ou seja, uma forma de resistência à submissão. A situação no trabalho não permitia mobilizar o sujeito além de um certo nível de subordinação, pois o mecanismo de proteção da saúde mental do trabalhador possibilita que este salvaguarde uma parte da sua liberdade. Não ser assíduo, desviar a atenção, não fazer exatamente o que o outro espera de você, é, de certa forma, dizer não à submissão, mas um não onde o resultado tem um sabor amargo, tais são os riscos de demissão, ou de reprovação pelo conjunto do coletivo de trabalho. Nesse sentido, nossos estudos precedentes mostram exemplos, como os que reproduzimos na Tabela 6

O que a psicopatologia mostra é que os trabalhadores sabem não só evitar essa atitude, mas também colocar em prática mecanismos de defesa "coletivos", que ao mesmo tempo os protegem do afrontamento com seus superiores hierárquicos, como permitem-lhes construir laços com seus colegas. Podemos pegar este exemplo como referência à idéia de uma "identidade positiva". O exemplo típico dado por Dejours é o da indústria química onde os operários faziam palavras cruzadas à noite, perto das máquinas que eles tinham que supervisionar, sob o olhar suspeito dos supervisores. Fazendo isso, o silêncio imposto pela tática do jogo permitia-lhes de estar atentos a eventuais barulhos ou odores que os alertariam para um funcionamento incorreto da máquina. Esse recurso ao jogo foi criado a posteriori pelos operários como uma reação ao estresse, fruto do senso de responsabilidade e do medo. Mas, ao mesmo 
tempo, esse mecanismo permitiu assegurar uma boa produção, evitar conflitos e sobretudo, exercer a criatividade.

Tabela 6 - Quais as razões mais freqüentes para a saída de um emprego?

\begin{tabular}{lrr}
\hline Motivos & Quantidade & \% \\
\hline Estudos & 9 & 24.4 \\
Reclamação do patrão & 30 & 10.1 \\
Atraso de salário & 2 & 0.5 \\
Baixo salário & 73 & 19,5 \\
Arrumar trabalho melhor & 22 & 5.9 \\
Discussões e intrigas & 45 & 12.0 \\
Mudança de patrões & 4 & 1.1 \\
Acusações de roubo & 19 & 5.1 \\
Doença & 6 & 1.6 \\
Não pagam a passagem & 1 & 0.3 \\
Alta exploração & 7 & 19.0 \\
Humilhação/maus tratos & 36 & 9.6 \\
Falta de confiança & 14 & 3.7 \\
Não ter direito aos feriados & 2 & 0.5 \\
Exigências em excesso & 23 & 6.1 \\
Não reconhecimento das qualidades & 3 & 0.8 \\
Trabalhar por conta própria & 1 & 0.3 \\
Necessidade de cuidar dos filhos & 3 & 0.8 \\
Não fazer os serviços corretamente & 14 & 3.7 \\
Gravidez & 7 & 1.9 \\
Não tem paciência com criança & 1 & 0.3 \\
Trabalhar longe de casa & 4 & 1.1 \\
Cansada de trabalhar no mesmo emprego & 24 & 6.4 \\
Não concorda com horários estabelecidos & & \\
pelos patrões & 1 & 1.1 \\
Muito serviço & 9 & 2.4 \\
Assédio & 100.0 \\
Patrões desonestos & 3 & 0.3 \\
Quer voltar para casa/terra natal & & 0.5 \\
\hline Total & 3 & \\
\hline
\end{tabular}

Fonte: IFPD - Instituto Fecomércio de Pesquisa e Desenvolvimento 
Nesse sentido, a condição para a construção de uma identidade positiva está na possibilidade de acesso à criatividade.

Além de existirem certas condições para o exercício da criatividade, que retomaremos mais à frente, como a confiança entre os pares, necessária à criação de uma linguagem comum, é preciso ainda acrescentar alguns elementos fundamentais sobre esta noção. Trata-se de uma pulsão e, como todas as pulsões, ela precisa se realizar. Para sermos mais claros, a sua não realização leva a um mal-estar, à doença ou à morte. A criatividade está ligada ao sofrimento e ao prazer. Não escapamos do sofrimento, pois ele tem a ver com as diferentes pressões com as quais nos confrontamos como trabalhadores. Pressões de ter que descobrir soluções para problemas do trabalho, que possuem sempre um eco de um sofrimento passado, já que nossa maneira específica e singular de encontrar soluções para os problemas tem a ver tanto com a nossa estrutura psíquica quanto com às condições sociais e, normalmente, nossas ações se situam dentro de uma ordem de repetição, até que seja possível, em certas condições, exercer em parte a criatividade. Não seria o prazer a diminuição do sofrimento? Dejours mostra que dar um sentido a nossas ações diminui o sofrimento. O alívio surge quando o podemos compreender.

Quando dito dessa forma parece muito simples, mas significa também que o prazer em reduzir o sofrimento está ligado ao exercício da criatividade. Às vezes, a compreensão dos problemas psíquicos, de configuração identitária, mostram que a sua origem está nos traumas sociais. Gaujelac (1989) salienta, por exemplo, que o fato de o indivíduo vivenciar uma situação de humilhação social, em razão de pertencer a uma família cujos pais contraem dívidas com os comerciantes da comunidade, pode impedir uma trajetória ascendente. Nesse sentido, novas condições sociais possibilitam, ao sujeito, ultrapassar esses traumas pessoais e se confrontar com o real, utilizando as capacidades que a sua situação social permite. Poder ter acesso à criatividade é poder medir a sua força. É renunciar à onipotência e à impotência e, portanto, conservar a sua saúde mental.É poder exercer sua capacidade de encontrar soluções conservando sua saúde mental. Uma boa parte dessa dinâmica pode ter viabilidade na forma cooperativa. 
No entanto, como afirma Dejours, se a criatividade é uma possibilidade à disposição de todos, ela só pode ser exercida em determinadas condições de exploração da mão-de-obra: um corpo cansado e dominado, sob precárias condições de segurança, impede o desenvolvimento de duas condições fundamentais à sua realização. Essas condições são: a confiança nos colegas, que permite a construção de uma linguagem comum de resistência, não forçosamente expressa por uma linguagem, mas por práticas (uma outra forma de linguagem) que a cada vez são reinventadas em função das características da situação dos membros implicados na dinâmica do grupo, do reconhecimento, da validação daquilo que produzem e da sua prática validada por seus pares e superiores hierárquicos.Uma boa parte dessa dinâmica pode ter viabilidade na forma cooperativa.

Este re-conhecimento significa nascer novamente a partir de uma relação onde nos é confirmado o nosso direito de existir. Esta busca de identidade é o que está em jogo na situação de trabalho. É também, e principalmente, o que buscamos no trabalho. Talvez seja isso o que é subtraído aos trabalhadores do setor informal e permitido àqueles das cooperativas.

Podemos, sem muito receio afirmar que, descobrir as características das identidades profissionais formadas em certas codições de trabalho, significa poder compreender, em parte, a lógica do social. Trata-se de uma das mais importantes esferas, o campo do trabalho, onde a socialização secundária se realiza. Se, partir da socialização primeira é possível saber a qual tipo de família pertencemos, segundo a socialização recebida, na socialização secundária reencontramos os valores imperativos sociais a partir da interiorização feita segundo a posição social que ocupamos e que exteriorizamos. Por que o trabalho seria uma das esferas de maior importância para a socialização secundária? Porque tudo o que somos está presente nas nossas ações, idade, cor, gênero etc. Verifica-se uma presença de todos esses elementos no ato do trabalho, mesmo se alguns deles são negados no trabalho prescrito ou formal. No entanto, estão sempre presentes na ação real. A análise deve revelar o que é naturalizado. Além disso, existem características identitárias que configuram o acesso a diferentes tipos 
de emprego. Hoje, alguns empregos precários são preenchidos pelas mulheres, negros, jovens e indivíduos oriundos de regiões específicas.

A identidade como um produto de relações subjetivas, exprime, através da sua configuração, a "qualidade" da relação com o outro. Não são todos os outros, ou quaisquer outros, que têm um lugar na configuração do sujeito mas, sem dúvida nenhuma, na esfera do trabalho, o olhar dos colegas ou dos superiores sobre ele é fundamental, e é frente a esses que nos posicionamos. Dessa forma, existe um processo constante de diferenciação que se efetua, relembrando, nesse sentido, a construção do "eles" e do "nós" dos estudos culturalistas já citados por Hoggardt (1970) ou Lewis (1967).

Entretanto, o trabalho se realiza através de um processo de grande submissão, com taxas de desemprego muito altas.

Sobretudo, as possibilidades de dividir experiências e de encontrar soluções conjuntas são bastante restritas. Ao invés de um "nós", mesmo que comunitariamente embrionário, existe um "eu" vulnerável. Um sujeito despojado de tudo, cuja identidade, diante de adversidades como a perda do emprego, ou a doença, não tem nenhuma solução possível, e é cada vez mais empurrado para a exclusão.

Observamos então, a repetição de situações onde a impotência e a frustração são as experiências mais freqüentes. Podemos notar que o sujeito está sempre em contato com a experiência da impotência. Nesse sentido, avançamos sobre a idéia de uma identidade negativa que se constrói socialmente a partir da experiência do trabalho, pois, o trabalho é um dos únicos meios que pode configurar a autonomia, e a autonomia é, como já vimos, o que dá acesso à criatividade.

Por outro lado, uma identidade pode ser pensada como "positiva" quando, numa relação, ela pode se fazer reconhecer nas suas necessidades, ter vínculos de negociação e conseguir que o outro respeite seus próprios limites. Cada um é detentor de poderes que permitem que a relação exista sem que nenhum membro seja massacrado pelo poder do outro. Em situação inversa, existem limites que, quando feridos, destróem o indivíduo. Lembramos, a este respeito, as declarações das empregadas domésticas se auto-definindo negativamente segundo suas 
próprias expressões: "nós não somos nem ladras, nem prostitutas, mas apenas domésticas" (Nunes, 1993). Falar de identidade construída negativamente no trabalho não significa que os trabalhadores não reajam às ofensas ou aos conflitos, mas que as soluções encontradas conduzem a rupturas e a uma grande rotatividade que os torna ainda mais frágeis. Nos casos anteriormente citados, as soluções não estão na negociação. Para que haja negociação, é preciso ainda reconhecer que as duas partes existem como limites, capazes de impor uma dinâmica à relação que poderia ser elemento de identidade positiva.

Algumas situações e condições de trabalho são particularmente nefastas. É preciso analisá-las não somente por não garantirem a sobrevivência econômica, nem a sobrevivência social, mas por colocarem em risco o tecido social. Não devemos nos enganar quando as instituições internacionais evocam o termo "trabalho decente", pois mesmo que ele permita uma remuneração ao menos modesta, este trabalho decente não permite existir socialmente.

Já vimos, em outros momentos históricos, uma fragmentação do trabalhador a partir da gestão do trabalho taylorista-fordista. Alguns autores chegaram à conclusão de que a identidade social se faria a partir do consumo. Os grupos se identificariam a partir do consumo. O problema está em que as transformações do trabalho como: o alto desemprego, as novas re-estruturações, terceirização, trabalho precário, trabalho em tempo parcial ou contrato com duração determinada, reconfiguram a socialização secundária e, a partir daí, a identidade social dos trabalhadores é permeada por um nível de heterogeneidade que só o consumo não poderia mostrar. A análise de diferentes elementos da crise do trabalho nos revela que os processos de identificação dos trabalhadores se fazem a partir de um perfil particular de exclusão. Se recolocarmos os três momentos da construção identitária, percebe-se que as expectativas são também ameaçadas.

\section{A título de conclusão}

O trabalho formal foi visto pelos autores clássicos e contemporâneos como permitindo a integração através da subordinação. O informal, após ter sido visto como um setor marginal, passou a ser 
percebido como uma possibilidade de inclusão num provável processo de formalização. Hoje, ele é visto como um setor onde a maioria dos trabalhadores pode se inserir. Uma nova socialização é, então, exigida em razão dessa situação: ensinar a cada sujeito como constituir capitais, buscar formação e formar redes, por exemplo, e como gerenciar esses capitais da melhor forma possível. Não podemos homogeneizar as situações no informal. Percebemos, ao privilegiar a análise da formação de identidade no trabalho, que as possibilidades desta constituição, para uma boa parte daqueles que ganham entre um e três salários mínimos, sempre foram muito frágeis. Trata-se de uma franja debilmente inserida e não integrada. Notamos que essa situação vem se agravando cada vez mais.

Por outro lado, quando uma parte dos membros do setor informal chega a se constituir em cooperativas, percebemos que uma identidade social diferente se desenha. Uma maneira de agir socialmente se manifesta e um engajamento social se afirma. Surge aí a construção de um "Nós" que permite um esforço em direção à integração social, mesmo quando a sobrevivência econômica é precária. No outro caso, é comum uma desintegração do tecido social comunitário, mesmo quando existe sobrevivência econômica. As formas de trabalho e as relações de trabalho promovem dinâmicas sociais a partir de identidades sociais que se formam historicamente.

Nesse sentido, as cooperativas nos deixam um ensinamento e uma reflexão: elas são novos atores que nascem de uma socialização no trabalho (secundária), mas que privilegiam os termos da socialização primária. Isso não diminui a importância da necessidade de compreender os limites e os benefícios na construção de um "Nós" a partir dos diferentes interlocutores que participam dessa experiência.

Há quase dez anos, temos visto novos atores surgirem na cena do cooperativismo. A partir dessas novas configurações nos perguntamos sobre como refletir a respeito da questão da autonomia e, portanto, sobre a criatividade que reconstrói a vitalidade do tecido social. Entretanto, na atual conjuntura, o setor informal, ao invés de ser um setor de "viração", "esponja de empregos", mostra uma ruptura social que se reatualiza e se aprofunda. 
Por isso, a partir dessas mudanças, o campo do trabalho nos permite reafirmar a sua centralidade para compreender a sociedade de hoje. Novas socializações se impõem relativizando o paradigma utilitarista, como o da racionalidade primária. No exemplo das cooperativas, vimos como as características próprias da socialização primária devem ser conservadas na socialização secundária, sem com isso negar a importância do mercado e do Estado. A racionalidade, relativa aos vínculos de mercado, de Estado e da sociedade civil, deve ser pensada conjuntamente nesses três níveis e nunca separadamente. É uma das pistas que as cooperativas podem nos dar para a reflexão. Isto é, repensar a concorrência, as alianças e as dívidas que contratamos.

Do ponto de vista da reflexão teórica, acostumamo-nos a refletir a partir do paradigma utilitarista, eficiência em função de fins, racionalidade econômica, custo e benefício presidindo trocas, as relações se esgotam na relação de mercado, já que tudo se torna mercadoria, e mesmo se essas ações racionais convivem muito bem com práticas arcaicas. A nosso ver, o que está acontecendo do ponto de vista empírico, na esfera de trabalho das cooperativas é uma luta contra os efeitos da "mercadorização" das ações sociais. Uma luta contra as ações guiadas pelo lucro, que querem ignorar o lucro social da integração, por exemplo. Ora, ignorar essa luta para atingir essa meta não é somente defender interesses político-econômicos, mas ignorar uma parte do funcionamento do social que necessita da "gratuidade" como a única condição da liberdade.

Nesse sentido, a reflexão sobre a relação entre a dívida e a dádiva nas redes, necessária para uma compreensão das cooperativas mais próxima da idéia de economia solidária, é também um dos aspectos importantes de nossas pesquisas. A dádiva existe em grande parte nas ações das redes, mas, sobretudo, este paradigma pode significar que o sujeito tem possibilidade de reconhecer sua subjetividade, estar plenamente presente na sua singularidade (jovens e velhos, homens e mulheres, etc.) e poder agir, a partir dela, sem naturalizá-la, constituindo vínculos nas diferentes redes. A perspectiva da dádiva implica a valorização e o reconhecimento de si e do outro na relação social. Nas novas gestões do setor formal, percebemos uma colonização da subjetividade, com os trabalhadores se submetendo aos ideais das 
empresas por medo do desemprego, como afirma Dejours. Existe uma mínima possibilidade do trabalhador se enxergar na sua singularidade.

Portanto, um eclipse da alteridade conduz então ao que Dejours chama de normopatia (por exemplo, uma indiferença ao que acontece a colegas que não tiveram tanta sorte). Simultaneamente, o processo de vulnerabilização do setor informal leva a um retraimento do indivíduo em relação à sua comunidade.

Diante do exposto, as cooperativas precisam, para conseguir sobreviver através das redes, ao mesmo tempo se valorizar e avaliar suas possibilidades, chamam a atenção para o reconhecimento necessário neste processo de suas singularidades e da alteridade. Isso se percebe quando as cooperativas se questionam sobre: com quem e de que maneira podemos construir vínculos e assim mostrar as condições de acesso à criatividade e, portanto, a uma identidade positiva? - isso permitiria ao sujeito exercer sua condição de ator. Ao estabelecer relações sociais para viver econômica e socialmente, o que podemos nos dar? o que queremos dar? com quais objetivos? o que esperamos do Estado? - São perguntas que as cooperativas se colocam e que poderiam permitir uma reflexão sobre o mundo do trabalho hoje.

\title{
Notas
}

1 Deslocalização é utilizado por nós para definir o mecanismo que as empresas adotam para desenvolver uma função de concepção em determinado local e uma função de execução em outro.

\begin{abstract}
The aim of this article is to discuss the impact on identities and the dynamics resulting from them, starting with different forms of insertion in the world of work; more specifically, beginning with the informal sector workers's socialisation and their cooperatives. Therefore, we consider the following elements underlined: workers in the informal sector who earn from one to three minimum wages; workers in cooperatives who earn the same amount; some concepts to understand identity at work and, finally, ties among those elements that help to perceive changes produced in the world of work itself.
\end{abstract}


Résumé. Notre but dans cet article est de reflechir sur l'effet, sur l'identité et sur les dinamiques qui en découlent a partir des différentes formes de gestion du travail. Plus spécialement à partir de la socialisation des travailleurs dans le secteur informel et dans les cooperatives qui recoivent entre un et trois salaires minimums. Ainsi nous abordons la question de l'identité au travail, dans ce contexte sócio-économique afin de percevoir les effets des différentes formes de travail sur l'identité.

\section{Referências bibliográficas}

CASTEL, Robert. Les metamorphoses de la question sociale. França : Fayard, 1995

CASTEL, Robert; HAROCHE, Claudine. Prorpiété privée, propriété sociale, propriété de soi:entretien sur la construction de l'idividu moderne. França : Faydard, 2001.

CAILLÉ, Alain. L'autre socialisme entre utilitarisme et totalitarisme. Revue du MAUSS, Paris, n. 16, 2000.

DIEESE. A situação do trabalho hoje. São Paulo, 2001.

DEJOURS, Christophe. Souffrance em France: la banalisation de l'injustice sociale. Paris : Seuil, 1998.

. Conferências Brasileiras. São Paulo : Fundap, 1999.

GAUJELAC, Vicent de. La névrose de classe. Paris : Hommes et Groupe, 1987. . Le coût de l'excellence. Paris : Seuil, 1996.

. La lutte des places. Paris : Desclée de Brouwer, 1996.

GODBOUT, J.; CAILLÉ, Alain. L'esprit du don. Montreal : Boreal Compact, 2000.

. Le langage du don. Montreal : Les Grandes Conférence, 1994.

. Le don, la dette e l'identité. Paris : La Découverte, MAUSS, 2000.

KJELD, Jakobsen; MARTINS, Renato; DOMBROWSKI, Osmir (Orgs). Mapa do trabalho informal. São Paulo: Fundação Perseu Abramo, 2000.

LAUTIER, Bruno. Trabalho ou labor? Dimensões históricas e cuturais. Revista Ser, Trabalho e cidadania, Brasília, n. 5, jul./dez. 1999. 
LAUTIER, Bruno; MIRAS, Claude de; MORICE, Alain. L'État et l'informel. Paris : L'Harmattan, 1991.

NUNES, Christiane Girard. Economia solidária em tempos sombrios. Revista SER, Brasília, 1999.

Relatório: empreendimentos econômicos e solidários. Brasília : UNITRABALHO, 2001.

POLANYI, Karl. A grande transformação. Rio de Janeiro : Campus, 2000.

SENNET, Richard. A corrosão do caráter. Rio de Janeiro : Record, 2000.

THEODORO, Mario; NUNES, Christiane Girard. Setor informal no DF: análise e desafios, relatório para a Secretaria do Trabalho do DF. Brasília, 2001.

A população do Varjão: Programa Habitar. Brasília. 